\section{DROPSY OF PREGNANCY.}

DROPSY OF THE FCETUS IN CONNECTION WITH DROPSY OF THE MOTHER, AND ITS IMPORTANCE IN THE QUHSTION OF INDUCTION OF LABOUR IN SUCH CASES.

BY WALTER S. A. GRIFFITH, M.B., Obstetric Physician to the Great Northern Central Hospital.

THE whole subject of dropsy of pregnancy requires much investigation; writers of general treatises of medicine appear to think it almost out of their province, and few obstetric authors refer to it, except incidentally, as a symptom often present in cases of puerperal eclampsia.

Much has been written discussing possible causes of the kidney disease which underlies it, but apparently, without a sufficient study of the natural history of these cases. Little do we know of the previous history and almost nothing of the subsequent history, and of the connection of the disease with the death of the patient, in cases where the patient survives, and apparently recovers from, the first and perhaps only attack of the disease.

The object of this paper is, however, to direct attention to the great mortality of foetuses in these cases, especially to one cause of this mortality, and to the bearing of this on the question of the induction of labour, which in the author's opinion is too often postponed in the supposed interest of the fœetus, and not without grave risk to the mother. The following case illustrates the main point.

Mrs. H., aged 29, was admitted into the Great Northern Central Hospital on June 4th, 1888, under the care of Dr. Griffith. Of her family history she knew nothing important. She believed she had had neither scarlet fever, rheumatism, nor any serious illness previously. She had had six children, no miscarriages, the youngest child being fourteen months old. She had had no serious complication in connection with her previous pregnancies. Her general health, though never robust, had been fairly good; she is dull, and perhaps somewhat deficient in intellect. The last menstrual period she stated was at the end of January, 1888, but from the size of the uterus and the development of the fœtus, as well as from the fact that she quickened on May 12th, pregnancy commenced probably a month earlier.

In March (the third month of pregnancy) she first suffered from severe frontal and vertical headache, nausea and vomiting; this had continued more or less since. She first noticed œedema of the face two or three weeks ago, and of the body and legs a few days later. The urine had lately become scanty, not containing blood. There had been diarrhoea for the last few days.

On admission, the face, abdominal walls, the back, vulva, and legs were much swollen; the peritoneum contained a moderate amount of free fluid, but there was none in the pleural cavities, and the lungs were not cedematous. The uterus reached nearly to the umbilicus, and fotal movements were felt. The temperature was normal, the pulse small and compressible; urine 32 ounces in twenty-four hours, acid, specific gravity 1022 , albumen about four-fifths. She slept well, was not drowsy during the day, but suffered much from headache and giddiness. The bowels were now costive. Beyond paleness of the fundi, corresponding to her general anæmic state, the ophthalmoscope revealed no abnormality.

Under a milk and light farinaceous diet, with iron and magnesium sulphate, aided later on by the compound jalap powder, the peritoneal fluid disappeared, and the headache was relieved; but at the end of a month the general œedema was still so extensive that it was decided to induce labour. The labia had twice been punctured, the distension being great, and the serum poured out from them in a continuous stream to the extent of 32 ounces.

On July 4th a bougie was introduced into the uterus; labour pains began twenty-four hours afterwards, and the fotus was born twelve hours later. It made some ineffectual respiratory efforts, but could not be kept alive for more than a few minutes. During the first week after this the dropsy rapidly diminished; the urine was abundant, and of low specific gravity, and contained less albumen.

On the 12th and 13th she had rigors, the temperature rising to $102^{\circ}$ and $103^{\circ}$, followed by profuse perspiration, and preceded by headache. There being no evidence that this depended on septic conditions, no change was made in the general treatment, and the ordinary carbolic douche continued. The breasts gave no trouble, having been firmly bandaged after the birth of the child. On the following day there was aching pain across the loins and abdomen, rather profuse diarrhœa and vomiting, frequent and painful micturition, and the urine contained blood. The left kidney was enlarged and tender. These symptoms continued, with only partial relief.

On the 20th the urine was smoky, specific gravity 1010, contained one-sixth albumen, and a little pus.

On the 24th there was tenderness in the course of the left popliteal vein, and some swelling of the limb, but not phlegmasia.

From this time she steadily lost ground, losing flesh and becoming melancholic; and in the second week of August, being violent and unmanageable, she was moved to the infirmary, where she improved, and was able to leave for a convalescent home in October.

On making a careful examination of the fotus it was found that, though there was little perceptible odema of the skin and cellular tissue, the serous cavities contained a considerable amount of fluid, that in the pleural cavities being sufficient to cause death when respiratory movements were needed. The lungs were partially inflated.

In cases of dropsy, such as this one, it frequently happens, as it does also in cases of considerable hæmorrhage during the later months of pregnancy, that great objection is felt by the medical attendant to interfering with the progress of pregnancy, and for what reason? Almost invariably in the supposed interests of the child, under the rule that every additional week in utero increases the chances of the ultimate survival of the child. But what is gained if it is stillborn? and what is lost to the mother by the delay? When the induction is put off until in the one case the uterus has to be emptied with great interference and haste owing to severe or protracted hæmorrhage, little thought being then given to the child born dead in the satisfaction that the mother's life is saved, if this is happily the result; and, in the other case, the woman lies for days and weeks hopelessly waterlogged, the dangers of labour and the puerperium increasing ; and though, as 8 rule, she makes a comparatively rapid recovery, she runs grave risk from asthenia, dropsy, eclampsia, hæmorrhage, phlegmasia, and septic infection, and little chance is there of the child surviving even if it is born alive.

The principles which should guide us in the management of cases in which considerable hæmorrhage occurs during pregnancy are absolute: to empty the uterus with as little delay and with as little risk as possible. This rule is clear and definite; the manner of carrying it out varies somewhat in different cases.

What rule should weadopt in the case of considerable dropsy of pregnancy? Treat the patient as a case of acute nephritis with dropsy ; if there is no distinct improvement within a reasonable period (from two to four weeks), and with less delay if the dropsy increases, empty the uterus. The best method for doing this is by the introduction of a clean bougie, leaving it until labour is established, a couple of five-grain doses of quinine being given at the end of twenty-four hours if the uterus needs further stimulation.

The rapidity with which the dropsy and the kidney symptoms diminish must not be taken as necessarily indicating a complete recovery, and the patient must be warned of the necessity of taking the greatest care of herself, and especially of the importance of not allowing herself to run the risk of pregnancy until a considerable time has elapsed and she is free from symptoms of renal disease.

\section{FUNCTIONAL (? RICKETY) INFANTILE PALSY,} WITH A NOTE ON "LINGUAL IRRITABILITY."

BY ANGEL MONEY, M.D., Assistant Physician to the Hospital for Sick Children, and to the University College Hospital.

THesr cases tend to prove the existence of paralysis of the spinal motor centres, not due to obvious lesions but yet destroying faradic irritability of the paralysed muscles. Unfortunately the peripheral nerves have not been examined. Diphtheria appears to be excluded. Whatever the cause may be, the mere existence of such cases in infants of so tender an age makes them of remarkable clinical interest.

E. G., a full-term child, aged eight months, was brought to me on September 1st, 1888, with the history that she was quite 
well until about nine weeks before, when she had an attack of "croup," probably spasmodic, as a doctor called in looked into the mouth ana saw nothing wrong. He further ordered hot baths, and the child recovered in three days; during the attack the hands were in a state of spasm, the fingers being bent; probably this was tetany with laryngismus stridulus. She remained quite well after this attack for fourteen days, after which some yellowness of the eyes with a squint, and twitchings of the limbs were noted; the squint being mostly convergent. Four days after these symptoms, the mother suddenly became aware of a general loss of power in the limbs, back, and neck. During the tirst three days of this powerlessness, also, the child was unable to suck the bottle, the milk running away from the mouth; the angle of the mouth was said to be drawn to the right, but against this the right eye was observed to be open during sleep. The child seemed not to have the strength to cry. The loss of power was not preceded by any definite attack of vomiting, fever, or other sign of acute onset. The back and the neck have recovered a little, otherwise the weakness has remained much the same, and ther has always been some power in the left hand. The state of the child strongly recalls that seen in the cases described by me in the Lancet, vol. ii, page 811,1888 ; the limpness of the paralysis was most marked, but there existed practically no toughening of the skin. None of the muscles of the body acted to the strongest faradic current, except the left muscles of the face, and these only imperfectiy. There was no tenderness anywhere, and no evidence of defective sensibility. The child's intelligence seemed in no way perverted.

A. T., aged 9 months, was brought on August 18th, 1887, on account of " fits" and weakness. By cross-questioning, it appeared that the former were most probably laryngismus stridulus. Facial irritability was present, most marked on the right side and about the orbicularis oris; the tongue was noted, also, to be too irritable, mechanical tapping of it causing decided contractions like those noted in the orbicularis oris. 1 shall call this " lingual irritat.ility." Perhaps this phenomenon is as common as the facial irritability for the writer has detected it in a few cases since the above. It is interesting to recall the belief of Gowers that the orbicularis oris is supplied from the hypoglossal nucleus.

On examining the soft palate and throat with the spatula an attack of child-crowing was induced. There can be no reasonable doubt that the laryngeal muscles and nervous correspondents were in the same irritable state as the facial and lingual centres and paths. I could not observe whether similar contractions followed stimulation of the palatal muscles; neither in this nor in other cases of the kind. The back and limb muscles were decidedly weak and limp. Curiously the palms and soles presented a slight condition of overarching, suggestive of tetany, but we could not ascertain that there had been any acute attack of this affection. The mechanical irritability of all the limb muscles was above par, but there did not appear to be any tenderness or thickening of the nerve-trunks. Faradic irritability in this case was present, but my impression from several trials was that it was decidedly diminished; the battery at Great Ormond Street that morning was not in good order. The child died in four days, probably in an attack of laryngeal spasm. Post-mortem examination made at home revealed no coarse lesion of the brain or cord. The latter was carefully microscoped. The nerves were not examined. The ribs were ridged, and decidedly rickety, especially the sixth rib. The baby had been fed artificially, and had had artificial foods. There was no reason to suspect syphilis; no teeth had been cut.

S. G., aged 10 months, was brought on April 3rd, 1888, in a state of general weakness and limpness, which bad developed rapidly during the previous week. There were marked signs of rickets at the junction of all the ribs with their cartilages and at both wrists; the jaw was toothless. The mother noticed nothing wrong except the weakness; she had not observed any spasms or child-crowing. There was no facial, lingual, or excessive mechanical irritability. The limbs held up went flop down; the child could not sit up, nor could it hold its head up. There was no retraction of the head, no fever, no loss of intelligence. The knee-jerks could not be obtained in the plantar reflexes; the muscles of the limbs did not react to faradism; those of the face acted normally. I regret that the galvanic current was not employed. There had been no history of sore throat.

The child continued to attend, but did not mend. At first the diaphragm acted; the intercostal muscles were not paralysed. But later the breathing became distressed; bronchitis developed, and death occurred in asphyxia on May 11th, 1888 . Altogether this case strongly recalled that of F. G., but the sclerema was practically absent. ${ }^{1}$ A necropsy was obtained, but the brain and cord were found to be healthy to the naked eye and microscope.

I believe other cases have come under my notice, but of these notes cannot be found. An apology is also needed for the meagreness of the above notes; but as the object of this paper is simply to direct at ention to an obscure but very important subject, any contribution is better than none, just as half a loaf is better than no bread.

\section{RECURRENT PNEUMOTHORAX.}

BY SAMUEL WEST, M.D., F.R.C.P,

Assistant-Physician to St. Bartholomew's Hospital; Physician to the Royal Free Hospital, etc.

Some months ago, Mr. Gabb published in the Journal, under this title, a most important and interesting case, in which there had occurred three attacks of pneumothorax with complete recovery. I had a similar case under my care at the beginning of this year at the Chest Hospital, Victoria Park, and it may be well, now that attention has been drawn to the subject by Mr. Gabb's case, to give also an acoount of my own.

W. H. D., aged 22, was admitted on January 3rd, 1888, into the Chest Hospital, Victoria Park, complaining of shortness of breath. The attack came on, he stated, without any apparent cause, on the morning of December 23rd, on getting out of bed. The breathing was so short that he found it necessary to remain at home, though he did not lie in bed; and, as after some days it still continued short, he applied for admission into the hospital. He had not felt ill or suffered in any way except with the shortness of breath.

The patient was a healthy-looking young man, slightly built, but well-developed and muscular. There was no evident dyspnœa. The shape and movements of the chest were symmetrical, but the percussion note was tympanitic over the whole right side from the apex to the base, back and front. The tympanitic resonance extended to the left edge of the sternum right down to the xyphoid cartilage, and the liver dulness did not rise above the seventh rib. The leart was displaced to the left, the apex beating under the left nipple. The vocal vibrations could be feebly felt and heard over the whole side, but the respiratory murmur was absent except at the base behind, where weak and distant amphoric breathing was audible. There was no bell sound or succussion. The lower edge of the liver could not be made out. The opposite lung was completely healthy, and the other organs seemed normal. The case was clearly one of pneumothorax without effusion, and in the process of resolution.

The subsequent history of the case is simple. The shortness of breath quickly disappeared. The patient looked and felt well, and gained flesh. The abnormal physical signs gradually vanished, and on February 6 th the following note was taken: "The shape of the chest is symmetrical, the movements free, but, on deep inspiration, there seems to be a little more expansion on the left side, especially in the axilla. The liver dulness begins at the sixth rib in the nipple line. The cardiac dulness is of its normal size, and the apex in the proper place. The percussion note is still a little more resonant on the right side; the breath sounds are distinctly audible and vesicular in character over the whole side down to the base. In the mid-axillary region a little fine crepitation is heard, probably pleuritic, for it is in this place that the patient has complained of pain for the last few days."

The patient's previous history was good. He had had no serious illness except scarlet fever and measles, but he had been regarded as a rather delicate child, having been subject to a cough on catching cold ever since an attack of bronchitis at the age of 3 years, but he lost his cough as he grew older. His father was living and well, but his mother died after a confinement. He had a brother and a sister, both strong; and he considered himself strong and active, and enjoyed athletic exercises.

Now comes the interesting part of his history. Last August, while walking quietly, he was suddenly seized with pain above the right clavicle, and felt a bubbling sensation in the right side. The breath at the same time became very short, and he had a rather violent cough-as he called it, a "churchyard cough"which he had not suffered from before the breath became short. $\mathrm{He}$ was able to keep at his work, however, but had to avoid all 